\title{
Egoísmo y comunidad: una lectura ética de La carretera
}

The Road | John Hillcoat | 2009

\author{
Boris Julián Pinto Bustamante* \\ Universidad El Rosario, Universidad el Bosque Bogotá- Colombia
}

Recibido: 14 de diciembre 2017; aceptado: 17 de septiembre 2017

\begin{abstract}
Resumen
La película La carretera (The Road), basada en la novela homónima del escritor americano Cormac McCarthy, propone una pregunta ética en un escenario post-apocalíptico: ¿cuál sería el canon moral que regule las relaciones humanas ante el colapso de la cultura capitalista? Esta pregunta conlleva una crítica a la moral preconvencional de una sociedad consumista y propone una ética elegida en situaciones límite a partir del reconocimiento de la dignidad humana. El presente artículo analiza esta propuesta a partir de tres elementos: el reconocimiento de los valores como contenidos morales que justifican las elecciones humanas; la comprensión de la ética como dimensión reflexiva de la moral, y la reivindicación de la ética del cuidado como alternativa a la ética individualista prevalente en la sociedad de consumo.
\end{abstract}

Palabras clave: Bioética | Cine como Asunto | Ética Narrativa | Valores Sociales | Comunidad

Abstract

The movie The Road, based on the novel by american writer Cormac McCarthy, proposes an ethical question in a post-apocalyptic scenario: what would be the moral canon that regulates human relations in the face of the collapse of capitalist culture? This question carries with it a critique of the preconventional morality of a consumer society and proposes an ethics chosen in limit situations based on the recognition of human dignity. This article analyzes this proposal from three elements: the recognition of values as moral contents that justify human choices; the understanding of ethics as a reflective dimension of morality, and the demand for the care ethics as an alternative to the individualistic ethics prevalent in consumer society.

Key words: Bioethics | Motion pictures as Topic | Narrative Ethics | Social Values | Community

Of course, in The Road there is no State, a fact which is crucial for an understanding of how the ethical system in question relates to the novel. For Schopenhauer, only the individual who accepts the moral boundary between right and wrong where no State or other authority guarantees it can truly be identified as just. Euan Gallivan Compassionate McCarthy?: The road and
schopenhanerian ethics. Children are the living messages
we send to a time we will not see. Neil Postman, 1982

\section{Introducción}

El junio de 2009 se estrenó La carretera (The Road), una película basada en la novela del escritor norteamericano Cormac McCarthy. Una historia intensa, violenta, pesimista, y a la vez, exuberante, sobre el derrotero de la civilización humana en un paisaje post-apocalíptico. Un padre y su hijo viajan hacia el sur durante años, tras el colapso de la civilización.

El libro no nos cuenta el origen preciso de la conflagración, pero la elipsis nos insinúa un desastre nuclear, una devastación natural, social, política y económica, tras la cual los sistemas culturales se han derrumbado definitivamente. El paisaje está devastado. Las montañas lucen estériles y una continua lluvia ácida bautiza la tierra. El padre y su hijo luchan por sobrevivir cada día. Los víveres escasean y no hay proveedores. No hay combustibles, no es posible sembrar nada en la tierra marchita. No hay estado, no hay derechos que puedan exigirse porque los jueces y los magistrados, o están muertos, o están mendigando en las carreteras. No hay iglesias que oficien la esperanza. El dinero vale lo mismo que un puñado de cenizas. No hay redes de comunicación, no hay máquinas trabajando y encontrar una Coca-Cola es un milagro en un paisaje de graneros sin maíz y árboles inclinados bajo el peso muerto de los hambrientos que cuelgan en sus ramas.

* boris.pinto@urosario.edu.co 
El país está infestado de devoradores. Muchos han decidido sumarse a las hordas de depredadores que recorren las carreteras en busca de comida. Andan armados de pistolas y cuchillos, de hachas y garrotes, husmeando algún manjar entre los despojos, robando sus zapatos a los muertos por el hambre (McCarthy, 2007).

Los hombres y las mujeres se mueven desorientados en un paisaje de ruinas. Se han convertido, al final, en "lobos para el hombre" (Hobbes, 1976). En el ocaso de la cultura, la violencia es el mayor de los miedos. Una sociedad que hizo del carrito del mercado el emblema del confort, ahora arrastra en armatostes oxidados los mendrugos de la miseria.

Los enjambres de felices consumidores que solían llenar sus carritos hasta el fastidio, recorren la carretera con los dientes afilados; se esconden en las orillas para cazar; encierran a sus víctimas en los sótanos y los mutilan con paciencia para alimentarse hasta el hartazgo. La adelantada sociedad del desahogo, anclada en la premisa del mutuo provecho (como lo ha planteado Morris Berman (Berman, 2007), parece no entender otra forma de relación: el consumo feliz, así se trate del consumo del otro.

Las hordas devoran a los indefensos que pueblan las carreteras y los montes. En medio de las tropas de carroñeros, el padre protege a su hijo de nueve años con las dos últimas balas que le restan en el tambor. Huyen, se esconden, visitan graneros desvencijados, casas solitarias, hurgan en los escondrijos. Cuando ya han comido las últimas manzanas, el padre y su hijo conversan:

\section{¿Qué pasa?, dijo el hombre.}

Nada.

Encontraremos comida. Siempre encontramos algo.

El chico guardo silencio. El hombre le observó.

No se trata de eso, ¿verdad?

Da igual.

Dimelo.

El chico desvió la mirada carretera abajo.

Quiero que me lo digas. No pasa nada.

El chico negó con la cabeza.

Mirame, dijo el hombre.

Se volvió y le miró. Parecía que bubiera estado llorando.

Habla.

Nosotros nunca nos comeríamos a nadie, ¿verdad?

No. Claro que no.

¿Aunque estuviéramos muriéndonos de hambre?

Ya lo estamos.

Tú dijiste que no.

Dije que no nos estábamos muriendo. No que no estuviéramos muertos de hambre.

Pero no lo haríamos.

No. No lo hariamos.

Pase lo que pase.

Pase lo que pase.

Porque nosotros somos de los buenos.
Si.

Y llevamos el fuego.

$Y$ llevamos el fuego. Asi es.

Vale

(McCarthy, 2007, pp. 75-76)

Pero, ¿y qué es el fuego?

\section{El fuego: una medida del mundo}

Debemos partir de algunas premisas: La carretera no es un opúsculo moral, ni McCarthy es un escritor confesional. Sin embargo, la obra lleva consigo, como los viajeros en su camino hacia el Sur, un fuego interior, un interesante ejercicio de ética narrativa. A través de un argumento preciso, de una historia cortante como los diálogos que la componen, de un paisaje alucinante pero imaginable y de unos personajes entrañables, la obra plantea preguntas urgentes.

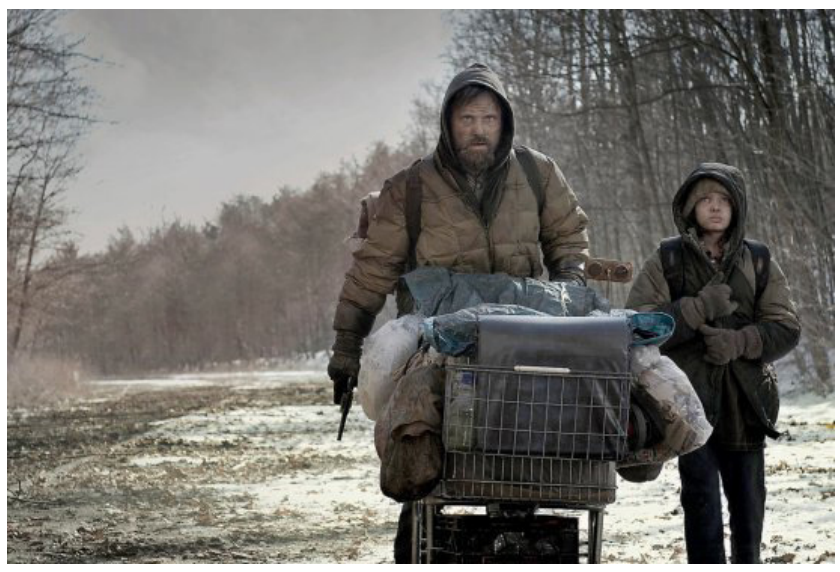

Cuando todo a nuestro alrededor ha colapsado, ¿por qué no devorar a los demás, si nos morimos de hambre?, ¿por qué no mutilar si nos persiguen los mutiladores del cuerpo? Cuando todo se ha derrumbado y los violentos detentan el atributo del colmillo y el garrote, ¿por qué insistir en cuidar a los débiles, o en proteger a los más pequeños?, ¿acaso no es la cultura una confección humana que difiere la violencia?, ¿acaso no son la moral y el altruismo, insumos biológicos para la supervivencia?, ¿qué sucede cuando las confecciones humanas se han derrumbado?, ¿puede permanecer, en medio del deterioro, algún vestigio de aquello que llamamos moral, más poderoso que la espada y el hambre? Nosotros llevamos el fuego, le repite el padre a su hijo, en la larga conversación que sostienen durante su viaje hacia el sur.

¿Qué representa el fuego? Algunos considerarán que se trata de un instinto. Otros atribuirán a las palabras del padre y su hijo en la carretera algún vestigio cultural 
que se niega a morir. Los más creyentes leerán en estas frases, cortas e incisivas, la permanencia del fuego divino en el corazón de los hombres. Otros, simplemente leerán aquí algunas insípidas frases de cajón. Es evidente, sin embargo, que las grandes obras suelen hacer grandes preguntas. Y esta es ya una gran obra; para muchos, un clásico instantáneo.

Muchas preguntas se pueden tematizar desde lo estético, desde la teoría literaria, desde la resonancia cultural de la obra. Otras premisas, además de la confección literaria, plantean cuestiones éticas esenciales. Siguiendo el ejercicio de ética narrativa que propone La carretera, el gran interrogante que hace la obra es una de las preguntas esbozadas por el niño a su padre:

Nosotros nunca nos comeríamos a nadie, ¿verdad?

[...] ¿Aunque estuviéramos muriéndonos de hambre?

[...] Pero no lo haríamos.

[...] Pase lo que pase.

[...] Porque nosotros somos de los buenos.

[...] Y llevamos el fuego

(McCarthy, 2007, pp. 75-76)

El niño plantea a su padre una pregunta sobre las razones últimas de la experiencia humana. Es un ejemplo notable de la mejor dialéctica socrática. Parte de una preocupación fundamental que el niño no puede ocultar por más tiempo a su padre:

Nosotros nunca nos comeríamos a nadie, ¿verdad? (McCarthy, 2007, p. 76)

Este es el argumento medular de toda la obra. Cuando han comido las últimas manzanas, y ya no hay latas de comida en el carrito, emerge la gran pregunta que también ronda la cabeza del padre. Frente a la posibilidad inminente de morir de hambre, ¿qué debemos hacer? No existe la posibilidad de negociar. El único alimento es el otro. Los padres devoran a sus hijos. Los hijos fuertes devoran a sus padres ancianos. Esta pregunta sobre el ¿qué debemos hacer?, cuando las opciones escasean o cuando cualquier decisión que tomemos es problemática, es una de las preguntas que procura responder la teoría ética.

Y la pregunta encierra una aseveración: Nosotros nunca nos comeríamos a nadie... la manifestación de una conducta elegida, libremente, por los miembros de una comunidad. La gran cultura humana ha colapsado, pero aún caminan en este paisaje de ruinas algunas formas de comunidad. Algunos se han confederado para asaltar a los más débiles. Estos confederados constituyen una "frágil e inestable comunidad moral" (Silberbauer, 2004, p. 58). ${ }^{1}$ No tienen historia porque no estiman el legado; no hay en ellos temor a ninguna forma de numen, ni invocan ley moral alguna. Su alimento es la carroña de los desvalidos. Puede que entre ellos exista algún intercambio de saberes, de lengua o de ficciones. Pero su ley es la ley -como sugiere $\mathrm{McC}$ arthy- del economato del infierno.

Débiles, desoladas, caminan otras pequeñas comunidades humanas. El padre y su hijo están vinculados por el amor, la sangre, y no por la confabulación. Se cuidan el uno al otro en el camino hacia el sur; se alimentan, intercambian temores y esperanzas. El padre, el hijo y el carrito de mercado constituyen una pequeña y frágil unidad doméstica: un oikos.

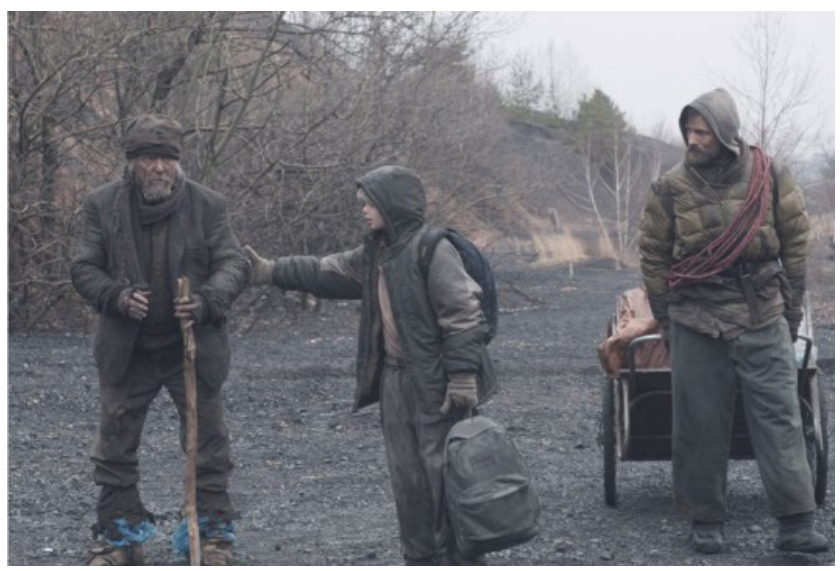

Bajó los prismáticos y se quitó la mascarilla de algodón que cubría su cara y se frotó la nariz con el dorso de la muñeca y luego miró otra vez. Se quedó allí sentado con los gemelos en la mano, viendo cómo la cenicienta luz del día cuajaba sobre el terreno. Solo sabia que el niño era su garantía. Y dijo: Si él no es la palabra de Dios, Dios no ha hablado nunca (McCarthy, 2007, p. 3).

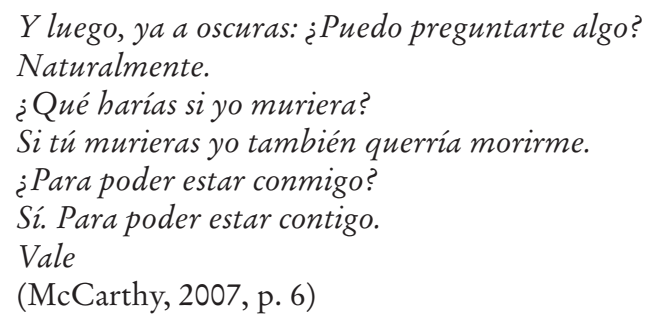

La comunidad moral que conforman el padre y su hijo ha elegido una conducta frente a la encrucijada que el hambre les propone. Pero tal elección no es simplemente un acto de voluntad. Tampoco es un aspaviento. Es una elección meditada, ponderada, que el padre ha considerado largamente, noche tras noche, mientras caminaban hasta este momento. Siguiendo la lógica dialéctica que el niño le propone, el padre se ve obligado a responder sin cortapisas. ¿Por qué? Es la pregunta que sigue a continuación. ¿Por qué hemos decidido, como comunidad moral, no comernos a nadie, pase lo que pase, aunque nos estemos muriendo de hambre? 
Porque nosotros somos de los buenos.

[...] Y llevamos el fuego

(McCarthy, 2007, p. 76)

La comunidad del padre y su hijo han elegido una concepción sobre aquello que consideran bueno. Puede que otros no compartan su opinión; pero ahora, en los límites del hambre, han decidido hacer una elección. Y toda elección es siempre una experiencia moral.

No estaba pensando en términos morales en ningún sentido; por el contrario (lo cual es casi lo mismo), estaba teniendo su primera experiencia profundamente moral. Estaba eligiendo un bando: lo normal. "Todo eso", como él lo llamaba, era lo que él elegía. Si el punto de vista científico lo apartaba de "todo eso", entonces imaldito fuera el punto de vista científico! La vehemencia de su elección casi le quitó el aliento; no habia tenido antes una sensación semejante (Lewis, 2006, p. 386).

Como escribió el poeta griego Odiseas Elytis, ellos han decidido ser "la bondad en el sendero de los lobos" (Elytis, 1976). Su decisión está dotada de un contenido, de un juicio que guía sus actos y precede sus decisiones. El fuego representa el contenido moral que justifica sus elecciones. Es un intangible. No es clara su sustancia ni tampoco su procedencia; pero su presencia es inevitable. Por lo mismo, por el peso que ejerce en las decisiones del mundo real, el fuego, si es una ficción, debe ser muy poderosa. Y nosotros llevamos el fuego. Pase lo que pase, ese fuego es un testimonio, es un majano muy elevado en la imaginación; es una estafeta que el padre, en su miseria, quiere legar a su hijo. Es evidente el contraste con las hordas de carroñeros. El gran desastre no es solo natural. Algo mayor se ha perdido en el descenso. En medio del invierno nuclear, dos pavesas arden aún en la más oscura noche del mundo.

Hay que recordar que "un valor es aquello que si desapareciera del mundo, creeríamos haber perdido algo importante" (Gracia, 2006, p. 28). El fuego es un valor porque se le extraña. Es una esencia, es un atributo, es una cualidad. Es un adjetivo que modifica a quien lo lleva. Aquel que lo tiene, lo cuida, lo cultiva y lo enseña porque lo considera valioso. Siguiendo a Diego Gracia (2006), la palabra cultivo proviene del vocablo latino colo, del cual se deriva también la palabra cultura (p. 23). Aquello que cultivamos sobre nuestra propia naturaleza, a eso llamamos cultura. Las jaurías de caníbales solo reconocen la cultura precaria del colmillo y el garrote. Han perdido, en su declive, el último reducto de aquello que, junto a la vulnerabilidad, parece peculiarmente humano, el atributo del fuego que modifica, que muda, que transforma, que enmienda a quien lo porta.
El ejercicio de valoración está presente en cualquier práctica de contemplación. La larga disputa sobre la naturaleza de los valores, la pregunta por si éstos son objetivos o subjetivos, si son temporales o eternos, si son universales o dependen de la perspectiva histórica de cada comunidad o aun de cada persona, es la larga lucha entre universalismo y relativismo. Al intentar definir las castas de valores estamos realizando, de paso, un ejercicio de valoración. No pretendo, en este punto, zanjar esta discusión atávica. Solo pretendo delinear una premisa: el valor, aquello que consideramos valioso, nos confiere una medida del mundo.

¿Tú eres de los buenos?

El hombre se quitó la capucha. Tenía el pelo largo y apelotonado.

Miró al cielo. Como si alli hubiera algo que ver. Miró al chico. Sí, dijo.

Soy de los buenos.

[...] ¿Y cómo puedo saber que eres uno de los buenos?

No puedes. Tendrás que hacer la prueba.

¿Lleváis el fuego?

¿Cómo dices?

Si lleváis el fuego

(McCarthy, 2007, p. 174)

El fuego es un valor, y tal valor, al convertir una cosa en un bien (siguiendo a Scheler), se trasfigura en símbolo y significado: "designa, por sobreabundancia de sentido, otro sentido indirecto, figurado, secundario, que no puede ser alcanzado sino a través del sentido primero" (Maceiras \& Trebolle, 1994, p. 217). Nosotros somos de los buenos, porque llevamos el fuego. El fuego que llevamos modifica lo que somos. Nos remite a otra condición. El valor deja de ser un ornamento para convertirse en contenido, en significado, en una presencia que nos habita, a la que no podemos asir pero que nos jalona, nos inquieta, nos inoportuna, nos incomoda hasta que le hayamos obedecido. El contenido que nos habita, al otorgarle una medida al mundo, se trasmuta en canon, en una vara de medir, en una pauta de justicia que se resiste a ser confinada en las palabras y promesas. Tendrás que comprobarlo. Aunque han sido destruidas las normas sociales y las reglas específicas que guiaban como ordenanza las conductas y las expectativas humanas, aún persiste en la memoria un valor poderoso que arde en la comunidad del padre y su hijo, y que se actualiza en la práctica del cuidado.

El ejercicio que propone el hijo a su padre no es llanamente el recuento de alguna moraleja. Es una pregunta que entraña un inaplazable contenido ético. Hemos hablado sobre la naturaleza de los valores. Tratemos de 
definir en adelante algunas generalidades sobre la ética y la moral.

\section{Ética y moral: algunas consideraciones}

Aunque etimológicamente, en sus raíces griega y latina, ambos términos hacen referencia a las costumbres y suelen usarse muchas veces como términos equivalentes e intercambiables, una aproximación más detallada revela alcances distintos para cada término.

En la historia de la ética son numerosas las definiciones que se han propuesto para definir satisfactoriamente ambos términos. Una de estas aproximaciones asocia la moral con la tematización de un conjunto de principios igualmente válidos para todos los seres humanos, desde una perspectiva universal (De Zan, 2004, p. 21), mientras que la ética hace referencia a "una concepción de la vida buena, a un modelo de la vida virtuosa, y a los valores vividos de una persona o de una comunidad" (De Zan, 2004, p. 22). Según esto, la moral es una teoría que intenta identificar valores y normas que definen, por acuerdo social y con pretensión universal, los términos correctos e incorrectos de la conducta humana, mientras que la teoría ética no tiene aspiraciones de validez universal; es histórica y socialmente construida.

Otros afirman, de forma escueta, que la moral es una hipótesis, una suposición sobre el bien y el mal, mientras la ética intenta fundamentar racionalmente tal proposición (Beauchamp \& Childress, 1999, p. 3). Una "teoría filosófica de la acción" (Beauchamp \& Childress, 1999, p. 18), que procura dar razón acerca de nuestras valoraciones y preferencias (Cortina, 2006, p. 19).

Otros definen la moral como el conjunto de hábitos, costumbres, valores, normas, preceptos, ordenanzas, concebidos al interior de las comunidades humanas. Los hábitos y las costumbres deseables requieren del establecimiento de un canon, de una medida, de una narrativa, de una vara recta que establece los límites y los términos socialmente acordados sobre aquello que es bueno, correcto y justo para cada persona al interior de su colectividad. La moral requiere de los vínculos humanos al interior de la comunidad para su supervivencia. El ingreso del hombre en la sociedad implica el ingreso en los límites morales establecidos históricamente por la cultura, a través de los diferentes espacios de socialización (familia, escuela, iglesia); se transmite verticalmente de generación a generación a través de la tradición, de la oralidad, de la escritura, del rito, del testimonio, y se ve influida por las dinámicas horizontales de interacción cultural, como son los medios de comunicación, los estándares de consumo, las migraciones.

Como afirma Cortina (2006): "despertar directamente actitudes porque se consideran más humanas o más cívicas que otras es inveteradamente una tarea moral, y se configura sobre la base de una concepción del hombre, sea religiosa o secular" (p. 17). Su presencia es fundamental para la construcción de los lazos históricos de las comunidades, para la supervivencia, para definir los rasgos que caracterizan a cada asociación humana, pero su ejercicio no entraña, necesariamente, una reflexión crítica sobre los fundamentos de las costumbres o sobre los fundamentos del canon que define los límites entre lo bueno, lo justo, lo correcto, al interior de cada comunidad.

La ética, por el contrario, implica la introducción de la reflexión crítica en el terreno de las costumbres (Hottois, 2007, pp. 35-36). En el momento en que nos formulamos una pregunta sobre el fundamento de nuestros hábitos, sobre cómo se legitima racionalmente un sistema moral, estamos ingresando en el terreno de la ética. Por ello, Séneca señala a Sócrates como el primer filósofo que indagó en la naturaleza de la ética, pues "puso la filosofía al servicio de las costumbres” (Sánchez, 1995). La ética, así entendida, es una ciencia derivada de la filosofía (como la ontología, la epistemología, la lógica, la estética) que indaga por cómo se fundamenta el fenómeno moral. La moral es el objeto de estudio de la ética (De Zan, 2004, p. 19).

[...] la ética no es una moral institucional. Por el contrario, el tránsito de la moral a la ética implica un cambio de nivel reflexivo, el paso de una reflexión que dirige la acción de modo inmediato a una reflexión filosófica, que solo de forma mediata puede orientar el obrar [...] (Cortina, 2006, p. 18).

Si la moral se corresponde con una suerte de hábitos, costumbres y tradiciones arraigadas en el seno de una comunidad que pretenden dotar de valor el contenido de las obras humanas y sus consecuencias, la ética se aparta de la simple concepción de la vida buena ofrecida por la tradición moral al cuestionar racionalmente las premisas fundamentales de tales presunciones ancladas en dicha tradición. Así, la ética es filosofía moral y es también realidad moral, pues el ejercicio reflexivo demanda una praxis como hecho moral. La reflexión ética acarrea interrogantes, decisiones, cambios de paradigmas o confirmación de los mismos. La reflexión ética trasciende el ámbito seguro de la especulación teórica, hasta los escenarios de la toma de decisiones morales en situaciones irrepetibles. 
Cortina ofrece una aproximación adicional: la moral es esa dimensión, que "puede expresarse a través de normas, acciones, valores, preferencias o estructuras", sin la cual nos veríamos obligados a "mutilar la comprensión sobre la realidad humana” (Cortina, 2006, p. 18), con lo cual nuestro mundo humano resultaría incomprensible. Pero esta dimensión humana, que obedece a un primer momento de valoración, de actitudes y preferencias, demanda luego un "segundo momento de sereno distanciamiento" (Cortina, 2006, p. 19), de reflexión, que encarna el momento ético. Por ello, a un primer momento de valoración, actitudes y preferencias en el diálogo del padre con su hijo en la carretera (Nosotros nunca nos comeríamos a nadie), le sigue un segundo momento de reflexión, suscitada por la pregunta del niño: (Porque nosotros somos de los buenos. Y llevamos el fuego).

Pero ¿de dónde proviene el fuego?, ¿de dónde provienen las valoraciones que hacemos, las preferencias y los juicios que guían nuestras elecciones? Esa pregunta también la plantea el niño a su padre.

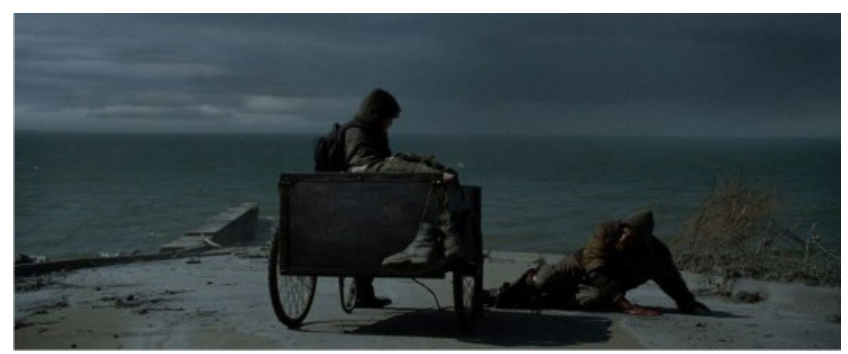

No. Tienes que llevar el fuego.

No sé cómo bacerlo.

Síque lo sabes.

¿Es de verdad? ¿El fuego?

Si.

¿Dónde está? Yo no sé dónde está el fuego.

Sí que lo sabes. Está en tu interior. Siempre ha estado abí. Yo lo veo

(McCarthy, 2007, p. 171)

Cómo lo hemos sostenido anteriormente, el fuego, la empalizada de valores y principios que sustentan el edificio de nuestras elecciones morales, si es una entelequia, es muy poderosa, precisamente por el movimiento que genera en el mundo, por las secuelas indudables que provoca. Nuevamente, la pregunta del niño a su padre es un generoso ejercicio de reflexión moral a partir de una legítima crisis de fe que necesita una confirmación por parte de su mentor. ¿Es de verdad? ¿El fuego? [...] ¿Dónde está?

En general, se han propuesto tres fuentes de autoridad para definir el origen de nuestras valoraciones: "la voluntad de una divinidad, el modelo de la naturaleza o el gobierno de la razón” (Ucko, 2001). Pero, ¿por qué existen los sentimientos morales? Puede existir una respuesta por cada uno de los orígenes citados.

John Rawls opina que "los sentimientos morales son necesarios para asegurar la estabilidad de la estructura básica de la comunidad con respecto a la justicia” (Rawls, 1971, p. 471). ${ }^{2}$ Thomas Hobbes sostiene que el hombre en su estado de naturaleza es un ser egoísta, violento, que no repara en ninguna forma de sentimiento moral para obtener lo que necesita del medio y de los otros; es un "lobo para el hombre" (bomo hominis lupus), y que solo la confección de un Leviatán, en el cual los hombres renuncian a algunas libertades a cambio de la seguridad que el estado (en la época de Hobbes una monarquía ya moderada por el Parlamento) les pueda ofrecer, puede postergar la violencia, por medio del miedo que inspira el Leviatán sobre sus súbditos. Hobbes es pesimista en cuanto a la posibilidad de encontrar en el hombre alguna forma de bondad esencial.

Otros, como Mary Midgley, sostienen que, más allá de "el mero terror mutuo de solitarios egoístas en coexistencia que invocó Hobbes para su contrato social” (Midgley, 2004, p. 41), los sentimientos morales contribuyen en la búsqueda de soluciones a los conflictos de cada comunidad, basados no en el temor recíproco, en el miedo cerval, sino en la simpatía activa, en los goces y las penas que surgen de la cooperación frente a problemas comunes (Silberbauer, 2004, p. 58). ${ }^{3}$

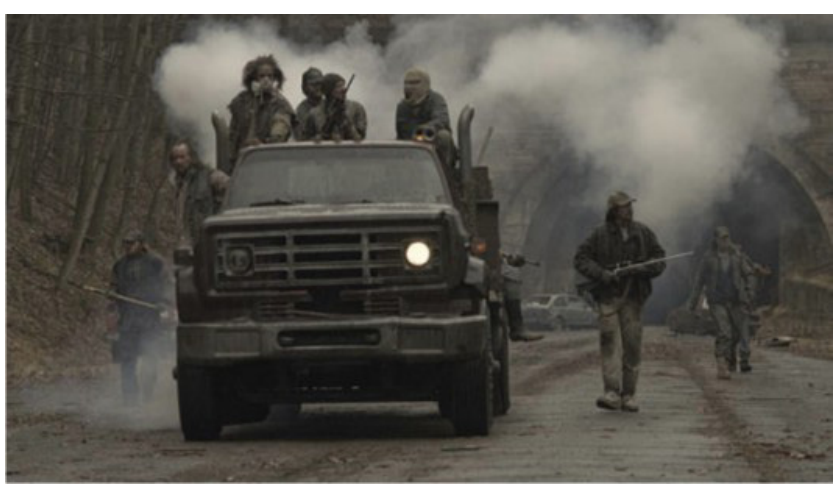

Es claro que la fuente de autoridad para las comunidades morales arraigadas en un credo religioso es la voluntad de la divinidad, confirmada a través de su expresión en textos canónicos, en la interpretación del magisterio y en la tradición histórica de la comunidad. En el caso de la tradición judía la revelación es interpretada por las autoridades religiosas, mediante la vivencia de la misnah. De la revelación proviene la expresión de la voluntad divina que, desde una perspectiva religiosa particular, es la fuente inobjetable de toda ley moral. 
A ello se refiere C. S. Lewis al definir lo que él llama la ley de la naturaleza humana, una suerte de ley que, a diferencia de las leyes naturales, el hombre puede decidir obedecer o no, una ley inscrita en la mente humana, no confeccionada por el hombre y que tampoco es el resultado de una ley natural o un desarrollo biológico. Varias son las premisas que utiliza Lewis para sostener la tesis de una ley moral proveniente de Alguien más allá de nosotros mismos:

- Primero, la enorme similitud que existe entre las distintas formas de leyes morales desperdigadas a lo largo de la historia en las distintas culturas. Existe, según Lewis, en cada comunidad moral un núcleo esencial de valores, de reglas, de principios de decencia, de sentidos de justicia que son comunes a toda comunidad. Pueden existir grados variables en cuanto a los procedimientos morales, pero no parecen existir, en un sentido más amplio, divergencias radicales sobre el núcleo de los valores que se consideran deseables. Si bien Mary Midgley no comparte "la simplicidad" del relato cristiano que Lewis intenta fundamentar, existen algunas aproximaciones convergentes en algunos trazos de su pensamiento: "Es obvio que las personas que se esfuerzan por comportarse decentemente a menudo están animadas por una serie de motivos bastante diferentes, directamente derivados de la consideración de las exigencias de los demás. Actúan a partir del sentido de la justicia, por amistad, lealtad, compasión, gratitud, generosidad, simpatía, afecto familiar, etc. - unas cualidades que se reconocen y honran en la mayoría de las sociedades humanas" (Midgley, 2004, p. 31).

Los hombres pueden diferir en cuanto a quiénes se debe proceder sin egoísmo (con los miembros de nuestra propia familia, con nuestros connacionales o con todo el mundo). Pero siempre han estado de acuerdo en que uno mismo no debe ponerse en el primer lugar. El egoísmo nunca ha sido admirado. Los hombres han diferido en cuanto a si se puede tener solo una esposa o cuatro; pero siempre ban estado de acuerdo en que no se puede simplemente tener la mujer que a uno le venga en gana. (Lewis, 2009, pp. 22-23)

- La ley de la naturaleza humana es una suerte de ley que, a diferencia de las leyes naturales, el hombre puede decidir obedecer, y que generalmente no se obedece de forma perfecta, pese a lo cual, aun aquel que no cree en la vigencia de las reglas humanas suele pedir disculpas cuando las quebranta. "Si no creemos en la conducta decente, ¿por qué entonces debemos mostrarnos tan ansiosos de presentar excusas por no habernos comportado decentemente?” (Lewis, 2009, p. 23).
- La incoherencia entre lo que se afirma y lo que se reclama por parte de quienes no reconocen la distinción entre las nociones de lo bueno y lo malo. Aun aquel que no considera la validez entre lo correcto y lo incorrecto, demanda respeto, consideración y alguna forma de desagravio cuando es objeto de cierta forma de injusticia (Lewis, 2009, p. 23).

Mary Midgley no coincide con la opinión de pensadores como C. S. Lewis, quienes "ensalzan las facultades humanas tratándolas como algo de especie totalmente diferente a las de los demás animales, de una forma que parece reclamar un origen diferente y no terrestre" (Midgley, 2004, p. 35). Para Midgley, siguiendo premisas de la sociobiología contemporánea, es posible rastrear comportamientos altruistas y de cooperación, más que de competencia, en especies animales no humanas, caracterizadas por un fuerte sesgo hacia la parentela más cercana, por prácticas de protección hacia los más débiles, e incluso por prácticas de reciprocidad a través de un "instinto social” (Midgley, 2004, p. 38) y de "disposiciones sociales naturales" (Midgley, 2004, p. 37), que son el origen de la moralidad. Tal instinto social, compuesto de rasgos heredados para garantizar "la supervivencia de los propios descendientes del altruista” (Midgley, 2004, p. 40), habría evolucionado hacia formas más sofisticadas en la elaboración de normas sociales como respuesta a los conflictos, gracias al desarrollo evolutivo de sus facultades mentales (Wilson, 1978, p. 167) (Rawls, 1971, p. 402).4,5

A esta propuesta sociobiológica, "el instinto de rebaño", C. S. Lewis responde afirmando que la ley moral no siempre se corresponde con el instinto más fuerte. Por el contrario, la ley moral suele ser, en términos de intensidad, más débil que otros instintos y, sin embargo, cuando prevalece, se le llama virtud. Un soldado que en la retirada tras un bombardeo a su base decide volver a rescatar a un compañero herido, quien no hace parte de su parentela próxima, seguramente será condecorado como un héroe con todos los honores militares. Un teólogo y filósofo alemán, Albert Schweitzer, quien un día decide estudiar medicina para viajar hasta Gabón en la Guinea ecuatorial para servir a los hombres y mujeres afectados por la lepra, además de promover la protección de los animales, mientras la mayoría de los miembros de su rebaño están empeñados en la guerra, es, por lo menos, la personificación de la más cara bondad. 
Supongamos que oímos el grito de alguien en demanda de auxilio. Probablemente sentimos en ese momento dos deseos: el de ayudar (instinto de rebaño) y el de no correr peligro (instinto de conservación). Pero dentro de nosotros, fuera de esos dos impulsos, se presenta un tercer factor el cual nos dice que debemos seguir el impulso de ayudar, y que suprime el deseo de salir huyendo. Aquello que establece un juicio entre los dos instintos, que decide a cuál de los dos instintos se debe obedecer, en sí mismo no puede ser ni uno ni otro. Sería como decir que una partitura musical, que en un momento dado nos dice cuál de las notas se debe tocar en el piano y no ninguna otra, es a la vez una de las notas del teclado. La ley moral nos dice la melodia que hemos de pulsar; nuestros instintos no son más que las teclas (Lewis, 2009, p. 25).

Por supuesto, la tradición cristiana se sentirá mucho más cómoda con la premisa de una ley moral proveniente de Alguien más allá de nosotros mismos, que con las teorías socio-evolutivas basadas en premisas biológicas y racionalistas. Ahora bien, no solo la tradición cristiana demanda un confort metafísico: "Schopenhauer insiste en que todo sistema ético demanda una base metafísica en orden a ser satisfactorio" (Gallivan, 2008, p. 5). Pero esta realidad sobre las divergencias en cuanto al origen de los sentimientos morales y en cuanto a su naturaleza solo nos indica el origen de las divergencias morales. Algunos empeñan sus esfuerzos en un sentido de la argumentación $y$ otros dedican su vida en el otro sentido. Mi intención, en este punto, no es demostrar la probidad de cada perspectiva. Este es el problema fundamental: no todos en nuestras sociedades actuales compartimos los mismos presupuestos, y aun muchos dentro de las mismas comunidades morales no concuerdan en todas las premisas sobre las cuales argumentan sus elecciones.

Esto no debería sorprendernos. La diversidad de perspectivas morales que componen el panorama religioso contemporáneo da cuenta de una indiscutible pluralidad de visiones que, con el paso de los años, solo parece multiplicarse. Como afirma Hugo Tristram Engelhardt, si bien los creyentes coinciden en que Dios es uno y se ha revelado a los hombres, tal parece, al mismo tiempo, que no todos escuchan de la misma manera el contenido, el tono y los matices de tal revelación (Engelhardt, 1995, p. 55).

A esta irreductible pluralidad de visiones algunos la denominan relativismo (Queraltó, 2008, pp. 10-11);6 otros le llaman pensamiento débil; otros, éticas de código múltiple (Morera, 2000, p. 516), en contraposición con las éticas de código único, o canónicas. Otros consideran que ambos términos son parientes cercanos. La primera acepción hace referencia a una postura de pen- samiento que no acepta la existencia de un único código moral universal al cual podamos suscribir nuestras elecciones morales; considera, por el contrario, que cada enclave cultural tiene una medida moral particular que no puede ser aplicada de forma simétrica y absoluta a otros entornos humanos.

Algunos autores definen esta premisa como uno de los rasgos característicos de la posmodernidad (otros se aventuran a hablar de ultramodernidad, hipermodernidad, modernidad radicalizada, entre otros simpáticos neologismos): una experiencia histórica caracterizada, entre otras cosas (y siguiendo a Lyotard), por el crepúsculo de los grandes metarrelatos que alimentaron las expectativas de emancipación de occidente fundadas en el predominio de la razón, así como por la imposibilidad de legitimar desde una única perspectiva racional el contenido de nuestras elecciones morales. En nuestras sociedades contemporáneas, caracterizadas por la creciente interconectividad, la aceleración de los flujos migratorios y la fragmentación de las visiones morales prevalentes, se hace imposible tratar de derivar un único código moral universal que sea vinculante a todas las personas en todos los contextos.

C. S. Lewis responderá a los relativistas de este cuño que tal divergencia de perspectivas no es otra cosa que una variación en los procedimientos, pero que la esencia de las preocupaciones morales sigue siendo la misma. Otros autores (como Sócrates en su pugilato con los sofistas) acuden en auxilio de la tesis de Lewis, al afirmar que "tal diversidad de creencias no refuta la posibilidad de que existan algunas creencias mejores que otras por ser más verdaderas o más justificadas que las demás" (Wong, 2004, p. 595).

Otra objeción, emparentada con la tesis de Lewis, considera que las variaciones morales son fundamentalmente variaciones superficiales motivadas por creencias religiosas o filosóficas privativas de cada cultura, pero que no alteran de forma definitiva la sustancia de los valores fundamentales (Wong, 2004, p. 596). La otra objeción proviene de la doctrina de los Derechos Humanos, la cual considera que existen aspiraciones éticas comunes a todo ser humano, en todo contexto cultural y en toda circunstancia, como son por ejemplo las aspiraciones éticas a la vida o a la libertad. Sin pretender violentar las fronteras de las cosmovisiones particulares, considera que, en general, existen tales aspiraciones humanas de carácter universal a las que hemos acordado en denominar derechos. Sócrates y Lewis coinciden en que parece conveniente situar una 
jerarquía de valores fundamentales más allá del alcance de las opiniones y del arbitrio humano.

Engelhardt no estará de acuerdo con estas premisas. $\mathrm{Su}$ tesis fundamental es la siguiente: en las sociedades posmodernas es imposible derivar una moral secular canónica y universal que provea de contenido las elecciones humanas. Esto no significa que no existan cánones morales. Significa, según Engelhardt, que la única forma de acceder a un canon moral, a una medida del mundo que proporcione contenido a las elecciones humanas es pertenecer a una comunidad moral (Engelhardt, 1995, p. 26). Solo al interior de una comunidad moral se puede ingresar en una narrativa moral particular que otorgue sentido a la experiencia humana. Solo la presencia de una fuerte narrativa moral puede otorgar instrucción moral, más allá de las normas externas o los simples procedimientos. Por fuera de una narrativa moral particular, la desesperación (Kierkegaard, 1979, p. 18), la norma vacua, el procedimiento insípido. En el río de una fuerte narrativa moral, la razón, el sentido, el contenido que otorga el espíritu a la norma.

Otra vez, no todos estarán de acuerdo con esta distinción. Alguien dirá: yo no pertenezco a ninguna comunidad moral, soy un tranquilo agnóstico que paga sus impuestos y no defrauda a su chica; respeto todas las creencias, pero en últimas, como Protágoras, soy la medida de mí mismo y de mi mundo. Yo también traigo el fuego y cuido de mis hijos con dientes y colmillos. Este puede ser el relato de lo que Engelhardt denomina un cosmopolita ecuménico que no se siente tan angustiado como el hombre sin conciencia eterna de Kierkegaard. Quizá tendremos que aceptar que su propia medida del mundo es su propia narrativa, aunque no pertenezca a una comunidad moral. También podemos añadir con Kierkegaard que: "los grandes hombres serán célebres en la historia; pero cada cual fue grande según el objeto de su esperanza: uno fue grande en la que atiende a lo posible; otro en la de las cosas eternas; pero el más grande de todos fue quien esperó en lo imposible" (Kierkegaard, 1979, p. 19).

Así podemos continuar eternamente y jamás pondremos de acuerdo a Lewis con Midgley o a Engelhardt con Kierkegaard. Pero todos (los cuatro autores que mencioné, y el resto de nosotros), aunque absolutamente otros, participamos de necesidades comunes.

\section{Ética, cuidado y posdeber}

Con esta pregunta y su fondo de solidaridad: mi casa es tu refugio, tu asilo, amigo, su rostro se despejó de pesares y sombras...

\section{Roberto Burgos Cantor, El hombre que perdió el norte}

Gilles Lipovetsky define la ética de los nuevos tiempos democráticos como una ética indolora que oscila en su movimiento entre una tendencia vivificante de la moral como bitácora del siglo XXI, como práctica saludable y necesaria en cualquier estrato de la dinámica social (tendencia revitalizadora de la cual, seguramente, es hija la bioética), y su contracara, como tendencia que desvela el declive creciente de la moral en una espiral de corrupción, individualismo y erosión de las virtudes públicas.

A un primer momento de secularización (1700 a 1950), en el cual el individuo autónomo, como corolario de la modernidad, se disuelve en su sacrificio "en el altar de la familia, la patria o la historia" (Lipovetsky, 2000, p. 11), como deudor del imperativo cuasi-religioso del "deber laico, rigorista y categórico" (Lipovetsky, 2000, p. 11), le sigue la ambivalencia de la ética contemporánea que se corresponde, según Lipovetsky, con un segundo momento en el proceso de secularización, al que él denomina el posdeber o el deber edulcorado (Lipovetsky, 2000 , p. 120). Este segundo momento se caracteriza por la promoción de las libertades y la autonomía individual, la cual, sin embargo, no naufraga en el nihilismo general ni en la anarquía o el hedonismo absorbente; por el contrario, la paradoja reside en que se instauran pautas sociales heterónomas de higiene y profesionalismo (como perfeccionamiento de sí mismo) que restringen los excesos de las libertades individuales en aras del bien colectivo, en lo que él ha llamado "una ética asimétrica, de geometrías variables” (Lipovetsky, 2000, p. 76).

"La globalización y su inclinación por la ley y el orden han avivado una regresión de la protección social hasta el mínimo hobbesiano, debilitando el Estado hasta un mero estado policial local” (Kottow, 2012, p. 48). El mundo bosquejado por McCarthy en su novela plantea un paso más allá del estado minimalista donde cada quien expresa en pólizas de seguridad su cerrado margen de protección privada. En este entorno social no es posible, siquiera, la emergencia de alguna forma de pauta social heterónoma fundamentada en la legitimidad de los consensos sociales, la tradición o el imperativo de la religión. No hay Dios y no hay estado. No hay polis. No hay por tanto ninguna posibilidad de aferrarse a convenciones 
sociales que legitimen las elecciones morales. La única forma de pauta heterónoma es el ejercicio ilegítimo de la violencia que impone los deberes y demanda sumisión.

La fuerza coercitiva del derecho es poderosa mientras exista la ficción humana a la que llamamos estado; pero es inexistente cuando este ha colapsado. Lo mismo puede decirse de la ética indolora de los nuevos tiempos democráticos. La promoción de su autonomía regulada y sus libertades individuales dirigidas solo es posible mediante artificios culturales como los estados sociales de derecho, el fetichismo contractual del mercado y los derechos universales. En ausencia de tales ficciones, su legitimidad es una ausencia terrible: "El mundo de $L a$ carretera es un mundo sin ley, a través del cual, bandas de ladrones al acecho, asesinos y caníbales intentan mantener sus propias existencias, esencialmente inútiles, a expensas de los débiles y vulnerables" (Gallivan, 2008, pp. 2-3).

Euan Gallivan (2008) explica desde la filosofía de Schopenhauer el correlato ético de La carretera. Para el filósofo alemán todo ser vivo expresa lo que él denomina el principio de individuación, la afirmación de su propia existencia frente al mundo. Este principio se manifiesta a través de la voluntad de vivir. Negar en el otro, tal voluntad de vivir como un principio básico, vital y universal constituye una acción incorrecta. La oposición a tal negación equivale a una acción justa (principio de la legítima defensa).

Schopenhauer identifica tres incentivos básicos de las acciones humanas: el egoísmo, la malicia y la compasión (Gallivan, 2008, p. 7). El primer incentivo se explica en el deseo de los peregrinos por sobrevivir, por cuidar de su parentela más próxima, aun si ello conlleva defender la propia vida contra la agresión de los otros, suprimiendo la vida del asaltante. En este caso, siguiendo a Schopenhauer, la negación del acto de negación (que supone la agresión de los violentos) se configura en afirmación de la propia voluntad de vivir y no corresponde a un equívoco moral. Tal oposición a la negación de la voluntad de vivir se justifica como defensa propia en situaciones límite, más no como represalia por hechos sucedidos (Gallivan, 2008, p. 8). Al incurrir el padre en el castigo y la venganza hacia el ladrón que les asalta en la playa, está incurriendo, en su desesperación, en el segundo incentivo de la conducta humana enunciado por Schopenhauer (la malicia).

El niño personifica a lo largo de la novela el hábito selectivo de la compasión. De la reciprocidad, más allá de la autenticidad; del reconocimiento, más que del conocimiento de sí (Lipovetsky, 1986, p. 60). De forma consis- tente, es el personaje que logra interiorizar el sufrimiento de aquellos que como él y su padre caminan temblando en la carretera plagada de antropófagos. Parece el único capaz de participar afectivamente en el sufrimiento de los otros, con los cuales se identifica en el mismo sufrimiento de los caminantes hacia la utopía del sur.

Pero no es el único. El pequeño de nueve años, tras la muerte de su padre, es acogido por una familia que cuida a sus dos hijos, los defiende con una escopeta y municiones de carga manual, lleva consigo un perro, no devora a los pequeños ni al animal y que en los pliegues de la historia, se revela, no como un grupo de forajidos sino como una pequeña comunidad que vigila al padre y su hijo en su marcha solitaria. Durante buena parte de la travesía, el padre y su hijo fueron cuidados, en la distancia, por otra comunidad que participó de su vulnerabilidad. Al final, como lo profetizó el padre, la bondad encuentra al niño (McCarthy, 2007, p. 172).

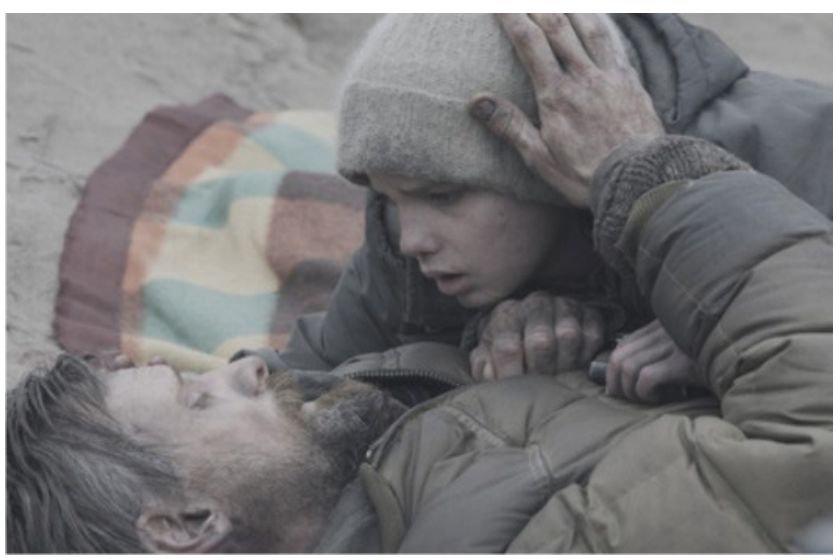

Cuando las convenciones sociales a las que nos hemos aferrado para diferir la violencia han colapsado, y no existe un estado que reivindique por medio del derecho y de la fuerza las prerrogativas y las aspiraciones generales o individuales, la alternativa a la violencia y la moral preconvencional de las mayorías precarias, habituadas a la lógica del consumo, es una ética elegida (en ello, concuerdo tangencialmente con Lipovetsky), no ya impuesta por el canon del deber rigorista y puritano, no ya impuesta por la fidelidad irrestricta a la patria o al cielo, sino impuesta en el ánimo del hombre por el hombre, o por la esperanza que lo habita, por virtud, por interés o por convicción. Está ética elegida es indolora si existe la confección del estado, el confort del mercado o el hogar metafísico; pero es punzante si la anestesia del confort individual desaparece.

$\mathrm{La}$ ética del cuidado, a la que finalmente remite $\mathrm{La}$ carretera, es una ética de máximos, es una ética elegida en situaciones límite, es una moral posconvencional. Con- 
cuerdo (otra vez con Lipovetsky y con Diego Gracia) en que hoy por hoy, dado el estado del arte de la secularización en occidente, el papel de la ética no se cifra en procurar intenciones puras (si bien es una opción privada el ejercicio de la virtud y una posibilidad deseable en los ámbitos públicos), sino en alcanzar soluciones intermedias, responsables, en el plano interindividual (Lipovetsky, 2000, p. 18). En ese sentido, una ética inteligente, es más una ética de la responsabilidad que una ética de las convicciones (Gracia, 1999, p. XI).

La ética del cuidado, como la han propuesto Gilligan y Noddings, y la ética de la protección, enunciada por Kottow y la corriente comunitarista, han evolucionado de forma interesante en las últimas décadas proponiendo, en el contexto de la globalización, la construcción de un entorno corporativo, político y económico sostenible a partir de un cambio de paradigma que privilegia el valor de la interdependencia mutua, la promoción de derechos fundamentales, la preeminencia de la justicia, la promoción de las virtudes de los ámbitos privados en los escenarios públicos de toma de decisiones y la responsabilidad intergeneracional, por sobre el paradigma fuerte del auto-interés y la competitividad salvaje del neoliberalismo (Hamington \& Sander, 2011). La ética del cuidado, las éticas de máximos y la bioética enfrentan el desafío de demostrar su pertinencia en un universo en el que la virtud no es un fin para todos, sino un medio para alcanzar resultados correctos, satisfactorios y responsables, siempre sobre la base del respeto por la dignidad humana, como fundamento de cualquier discusión en torno los conflictos de valor. Enfrentan a la vez, el desafío de amplificar las perspectivas en torno a la naturaleza de las relaciones humanas en el contexto de las sociedades contemporáneas.

No obstante, en los ámbitos privados seguimos extrañando el cuidado de los seres que comparten con nosotros las incertidumbres de la carretera. En el declive de los deberes y las convicciones fuertes existe una razón para perseverar en el cultivo del fuego:

Él tosía todo el tiempo y el chico le veía escupir sangre. Caminando encorvado. Mugriento, andrajoso, desesperanzado. Se detenía y se apoyaba en el carrito y el chico seguía andando y luego paraba y miraba atrás $y$ él alzaba sus ojos llorosos y lo veía alli de pie en la carretera mirándole desde un futuro inimaginable, resplandeciendo en aquel páramo como un tabernáculo (McCarthy, 2007, p. 168)

El otro puede ser una garantía frente a la desesperanza. Es el motivo del fuego que llevamos en medio del invierno. El otro, al que cuidamos, puede ser un tabernáculo que resplandece en medio de la nada. Es la personificación del ofrecimiento, de la renuncia, de la responsabilidad. En la ética del cuidado, el otro es el fin de nuestras fatigas y nunca, el instrumento de nuestros apetitos. A esto, algunos le llaman dignidad. El padre cuida a su hijo; el hijo cuida de su padre. Una familia de desconocidos, quienes aún se reconocen como miembros de una comunidad de seres vulnerables, cuida de los dos en el camino infestado de los devoradores del cuerpo.

La mujer al verle lo rodeó con sus brazos y lo estrechó. Oh, dijo, me alegro tanto de verte. A veces le hablaba de Dios. Él intentó hablar con Dios pero lo mejor era hablar con su padre y eso fue lo que bizo y no se le olvidó. La mujer dijo que eso estaba bien. Dijo que el aliento de Dios era también el de él aunque pasara de hombre a hombre por los siglos de los siglos (McCarthy, 2007, p. 176).

\section{Referencias}

Beauchamp, T., \& Childress, J. (1999). Principios de ética biomédica. Barcelona: Masson.

Campbell, T (2011). Improper life. Technology and biopolitics from Heidegger to Agamben. Minneapolis, MN: University of Minnesota Press.

Cortina, A. (2006). Ética minima. Madrid: Tecnos.

De Zan, J. (2004). La ética, los derechos y la justicia. Montevideo: Fundación Konrad-Adenauer Uruguay.

Elytis, O. (1976). I kalosini stis likoporiés [La bondad en el sendero de los lobos]. Edición especial, obra del grabador Dimitris Papagueorguiu, Madrid.

Engelhardt, T.H. (1995). Los fundamentos de la bioética. Barcelona: Ediciones Paidós Ibérica.

Gallivan, E. (2008). Compassionate McCarthy?: The Road and Schopenhauerian Ethics. The Cormac McCarthy Journal, 6, 98-106.

Gracia, D. (1999). Prólogo a la edición española. En Beauchamp, T., \& Childress, J., (eds). Principios de ética biomédica. Barcelona: Editorial Masson.

Gracia, D. (2006). Contribución de las humanidades médicas a la formación del médico. Humanitas. Humanidades Médicas.

Hamington, M. \& Sander-Staudt, M. (eds.). (2011). Applying care ethics to business. New York: Springer.

Hobbes, T. (1976). Leviathan. London: Forgotten Books. 
Hottois, G. (2007). ¿Qué es la bioética? Bogotá: Universidad El Bosque.

Kierkegaard, S. (1979). Temor y temblor. Buenos Aires: Editorial Losada.

Kottow, M. (2012). From justice to protection. A proposal for public health bioethics. New York: Springer.

Lewis, C.S. (2006). Esa horrible fortaleza. Barcelona: Minotauro.

Lewis, C.S. (2009). Mere Christianity. New York City: Harper Collins Publishers.

Lipovetsky, G. (2000). El crepúsculo del deber. La ética indolora de los nuevos tiempos democráticos. 5ta ed. Barcelona: Anagrama. Lipovetsky, G. (1986). La era del vacío. Ensayos sobre el individualismo contemporáneo. Barcelona: Anagrama.

Maceiras Fafián, M. \& Trebolle Barrera, J. (1994). La hermenéutica contemporánea. Madrid: Ediciones Pedagógicas.

McCarthy, C. (2007). La carretera. Barcelona: Mondadori.

Midgley, M. (2004). El origen de la ética. En Singer, P. Compendio de ética. Madrid: Alianza Editorial.

Morera Pérez, B. (2000). Aspectos bioéticos de la asistencia al drogodependiente. Adicciones, 12(4), 516.

Queraltó, R. (2008). La estrategia de Ulises o ética para una sociedad tecnológica. Sevilla: Dos Ediciones.

Rawls, J. (1971). Theory of justice. Cambridge, MA: Harvard University Press.

Sánchez, F. (1995). Temas de ética médica. Bogotá: Giro. Recuperado de http://www.encolombia.com/etica-med...

Silberbauer, G. (2004). La ética de las sociedades pequeñas. En Singer, P. Compendio de ética. Madrid: Alianza Editorial.

Ucko, H. (2001). El compromiso ético judeo-cristiano. Relaciones judeo-cristianas ideas y temas actuales del diálogo cristiano-judío. Esta disertación fue ofrecida durante la conferencia internacional del ICCJ (Consejo Internacional de Cristianos y Judíos), que se realizó en Montevideo, Uruguay. Recuperado de http://www.jcrelations.net/el+compr...

Wilson, E.O. (1978). On human nature. Cambridge, MA: Harvard University Press.

Wong, D. (2004). El relativismo. En Singer, P. (Ed). (2004). Compendio de ética. Madrid: Alianza Editorial.

1 George Silberbauer hace una interesante anotación acerca del desplazamiento de los Ik, en Uganda del Norte, de su entorno natural y su "matriz de significados culturales", lo que parece haber conducido al menoscabo de sus relaciones sociales: "Los Ik, abandonados en un terreno montañoso casi árido, desecharon su orden social y moral, antiguamente comparable al de los G/wi, para llevar una vida de competencia feroz. La descripción que hace Turnbull no es de violencia brutal sino de una indiferencia trágica y fría. Entre los Ik, el límite de respeto a la vida del grupo parece haberse retraído hasta el más cerrado autointerés (...) ¿Son los Ik un pueblo sin sociedad y por lo tanto descalificados para las generalizaciones acerca de valores éticos y morales universales? Este sería un argumento especioso y de carácter circular: (...) no existe ninguna sociedad sin moralidad, por lo tanto, todas las sociedades tienen una moral. Lo que tienen es un orden social pero frágil e inestable, basado en la explotación de los débiles por los que tienen la fuerza en cada momento, y que se abstienen de explotar hasta la muerte solo porque mañana necesitarán de nuevo a los débiles para explotarles más.” Silberbauer, G. (2004). La ética de las sociedades pequeñas. En Singer, P. Compendio de ética. Madrid: Alianza Editorial. p. 58-59.

2 John Rawls afirma al respecto: “En su forma más reciente y desarrollada (el origen de los sentimientos morales) se representa por la teoría del aprendizaje social. Una de las principales controversias es si el objetivo de la instrucción moral es suplir los motivos que hacen falta: el deseo de hacer lo que es correcto para su propio bien, y el deseo de no hacer lo que es incorrecto. La conducta correcta es generalmente una conducta benéfica para otros y para la sociedad [...] mientras la conducta incorrecta es un tipo de comportamiento generalmente ofensivo hacia los otros y hacia la sociedad, frecuentemente, para hacer aquello para lo que tenemos un motivo suficiente [...]”. Rawls, J. (1971). Theory of justice. Cambridge, MA: Harvard University Press. p. 401.

3 Siguiendo con el caso de los Ik en Uganda del Norte, que también relata Colin Turnball en The Mountain People, se trata de una comunidad desplazada de sus valles fértiles, en un proceso de dislocación geográfica, cultural y moral, que desplazó no solo sus actividades productivas, sino sus significados simbólicos y el sistema moral que gravitaba alrededor de sus redes de reciprocidad y sentimientos comunitarios, degenerando, como hemos anotado, en prácticas morales caracterizadas por la "competencia feroz" y una "indiferencia trágica y fría”. Silberbauer. Ibíd., p. 58.

4 La teoría sociobiológica del origen y el papel de la moralidad, así como las teorías deterministas desde el patrimonio genético, han ganado una importante atención sobre el origen de las normas humanas que guían el comportamiento. "Los genes sujetan a la cultura con una correa. La correa es muy larga, pero inevitablemente los valores serán constreñidos de acuerdo con sus efectos sobre el acervo genético. El cerebro es un producto de la evolución. El comportamiento humano -como las capacidades más profundas para la respuesta emocional que lo guían y conducen- es el circuito técnico por medio del cual el material genético ha sido y será mantenido intacto. La moralidad no tiene otra función primordial que pueda ser demostrada”. Wilson, E. O. (1978). On human nature. Cambridge, MA: Harvard University Press, p. 167.

5 En este punto, se superpone la teoría racionalista sobre la teoría naturalista, al definir la aparición de los sentimientos morales como un paso evolutivo del ser humano como ser racional: "La otra tradición del aprendizaje moral deriva del pensamiento raciona- 
lista y es ilustrado por Rousseau y Kant, y algunas veces por J. S. Mill, y más recientemente por la teoría de Piaget [...] Una vez los poderes de la comprensión maduran y las personas llegan a reconocer su lugar en la sociedad y son capaces de aceptar la perspectiva de los otros, ellos aprecian los beneficios mutuos de establecer términos justos de cooperación social. Tenemos una simpatía natural con otras personas y una susceptibilidad innata a los placeres de la empatía y el dominio de sí mismo, y estos proveen la base afectiva para los sentimientos morales, una vez tenemos una clara comprensión de nuestras relaciones con nuestros asociados desde una apropiada perspectiva general. Así, esta tradición considera los sentimientos morales como una consecuencia natural de una cabal apreciación de nuestra naturaleza social”. Rawls. Op. cit., p. 402.

6 Concuerdo con la tesis de Ramón Queraltó sobre la agenda política del relativismo moral: “Ahora bien, el problema del relativismo es que, a nivel social general, antes o después, acostumbra a favorecer a los más fuertes y perjudicar a los más débiles, o como afirma el refrán popular “a río revuelto ganancia de pescadores”. Porque, en verdad, la actual sociedad tecnológica y globalizada es sin duda un río revuelto, en el que la tarea de saber a qué atenerse en la vida -columna vertebral de una existencia humana en mínimo bienestar- resulta poco menos que una tarea de héroes, figura antropológica sin demasiado atractivo para el hombre de una sociedad de consumo. Ante el río de aguas turbulentas, sálvese quien pueda privadamente y no se busque un asidero moral "demasiado fino" porque tampoco se puede estar seguro de estar en lo cierto, ya que a fin de cuentas todas las posibles justificaciones y metarrelatos poseerían un valor semejante, con tal de dejar vivir mínimamente al prójimo. En suma, esto conduce a la parálisis moral de la acción humana en ciudadanía, dejándose las manos libres a quienes ostentan el poder real en la sociedad, especialmente a dirigentes económicos y culturales que naturalmente actúan según unos objetivos bien delimitados, claros y precisos. En una palabra, el relativismo moral es un arma magnífica para mantener "el sistema”, el “establishment”, o como quiera llamársele”. Queraltó, R. (2008). La estrategia de Ulises o ética para una sociedad tecnológica. Sevilla: Dos Ediciones. pp. 10-11. 